RESEARCH PAPER

\title{
CHEMICAL FRACTIONATION OF LEAD, COPPER, ZINC AND CADMIUM IN SOILS ALONG THE HIGHWAY FROM TAFO TO ABOASO IN THE ASHANTI REGION OF GHANA
}

\author{
J. K. Adengala ${ }^{1}$, R. B. Voegborlo ${ }^{2}$ and J. I. Adam $^{3}$ \\ ${ }^{1}$ Department of Environmental Science, Faculty of Biosciences, KNUST, Kumasi, Ghana \\ ${ }^{2}$ Department of Chemistry, Faculty of Physical Sciences, KNUST, Kumasi, Ghana \\ ${ }^{3}$ Department of Theoretical and Applied Biology, Faculty of Biosciences, KNUST, Kumasi, Ghana \\ Corresponding author: email raybrightv@yahoo.com; rbvoegborlo.sci@knust.edu.gh
}

\begin{abstract}
:
Knowledge of the mobility and bioavailability of heavy metals in soils is necessary for the design of remediation processes and the establishment of environmental guidelines for heavy metal pollution. Single extractions were used to fractionate four heavy metals $(\mathrm{Pb}, \mathrm{Zn}, \mathrm{Cu}$ and $\mathrm{Cd})$ from a total of fifty-four roadside soil samples into four operationally defined groups: acid soluble, reducible, organic and residual fractions. $P b$ was mostly bound to the reducible fraction (51.14\%). The next most important fraction for $P b$ was the residual fraction (21.98\%) followed by the acid soluble fraction (14.15\%) then the organic fraction (12.73\%). Zn was mostly associated with the residual fraction (48.37\%). The percentages of $\mathrm{Zn}$ bound to the reducible and acid soluble fractions were $38.95 \%$ and $6.64 \%$ respectively. The organic fraction contained $6.04 \%$ of total $\mathrm{Zn}$. The trend of $\mathrm{Cu}$ distribution among the fractions was: organic fraction (48.59\%), reducible fraction (25.61\%), residual fraction (20.58\%) and acid soluble fraction (5.01\%) while that of Cd was: reducible fraction (45.09\%), the acid soluble fraction (34.71\%), residual fraction (20.19\%) and organic fraction (0.00\%). The percentage of the metals which were found to be bioavailable and the order of potential bioavailability was: $\mathrm{Cu}(79.21 \%)>\mathrm{Cd}(79.16 \%)>\mathrm{Pb}(77.97 \%)>\mathrm{Zn}$ $(51.55 \%)$.
\end{abstract}

Keywords: chemical fractionation, roadside soil, lead, copper, zinc, cadmium

\section{INTRODUCTION}

Soil has long been regarded as a repository for society's wastes (Chlopecka et al., 1996). Soil contaminants can pollute water supplies and impact food chains when gradually mobilized by biogeochemical processes. There is a concern to know the metal bioavailability and toxicity to plants, animals and man, the efficiency of the soil as a sink for metals and the potential capacity of a metal to be mobilized from the soil.
Heavy metals are naturally present in soils, water and air. However, roadside soils have been reported to contain high concentrations of metallic contaminants as studies have shown that soils receive extremely large inputs of toxic metals from different anthropogenic sources and especially from automobile emissions (Ho and Tai., 1988; Garcia and Millan, 1998). Metals such as Copper( $\mathrm{Cu})$, Iron( $\mathrm{Fe})$, Zinc(Zn), and Cadmium $(\mathrm{Cd})$ are essential components of many alloys, wires, tires, and many 
industrial processes, and could be released into roadside soils and plants as a result of mechanical abrasion and normal tear and wear. For example, lead in street dust and roadside soil has been extensively studied, and found to be present at elevated levels (Page et al., 1971, Goldsmith et al., 1976; Harrison et al., 1981). The concentrations of lead in soil and in plants along major urban highways have been shown to decrease rapidly with distance from the roadside and with decreasing traffic density (Motto et al., 1970; Page et al., 1971; Ward et al., 1977). Tam et al., (1987) used surface soil in a survey of roadside heavy metal contamination in Hong Kong and found a significant correlation between traffic density and $\mathrm{Pb}, \mathrm{Cu}$ and $\mathrm{Zn}$ concentrations.

At present, it is widely recognized that the distribution, mobility and bioavailability of heavy metals and radionuclide in the environment depends not only on their total concentration but also on the association form in the solid phase to which they are bound (Ure et al., 1995; Ure and Davidson, 2001). Some variations of the chemical or physical conditions in the environment can accelerate to some extent the release of toxic metals into it, thus causing contamination. Bioavailability of heavy metals also depends greatly on the characteristics of the particle surface, on the kind of strength of the bond and on the properties of the solution in contact with the solid samples. Based on primary accumulation mechanisms in soils, heavy metals can be classified into several fractions. The fractionation of heavy metals in soils has been studied by many researchers (Tessier et al., 1979; Hickey and Kittrick, 1984; Ure et al., 1995; Wassey et al., 2001; Jaradat, 2002). Tessier et al., (1979) proposed the separation of heavy metals in soils into water soluble, exchangeable, carbonate bound, Fe-Mn oxides bound, organic bound and residual fractions by sequential extractions.

Numerous sequential extraction schemes (SES) have been proposed by many other authors (Meguellati et al., 1983; Shuman, 1985; Salo- mons and Förtsner, 1980; Elloit et al., 1990; Ure et al.,1995; Krishnamurti et al., 1997). Most include a number of stages between 3 and 8 with varying conditions and extractants. In an attempt to harmonize the different schemes, one originally proposed by the Community Bureau of Reference (BCR SES) allows the separation of extractable metals into three fractions, i.e. acid soluble, reducible and organic. Other schemes also include a residual fraction to make up four fractions. The acid soluble fraction includes the water soluble and exchangeable fractions of the Tessier classification. This fraction contains metals which are precipitated or co-precipitated with carbonates, metals adsorbed on solid surfaces by weak electrostatic interactions, metals that can be released by ion-exchange processes and water soluble species made up of free ions and ions complexed with soluble organic matter. The acid soluble fraction constitutes the most mobile and potentially the most available metal species. The reducible fraction contains metals bound to manganese and iron oxides. Hydrous oxides of manganese and iron are extracted together. The organic fraction contains metals bound to organic matter and sulfides. The residual fraction contains metals bound to mineral matrix. This fraction constitutes the metals that are least mobile and available to living organisms.

Sequential extraction is frequently applied for the fractionation of solid phase associated elements in soils and sediments (Pickering, 1981; Lund, 1990; Ure, 1990; Tack and Verloo, 1995). This has been used to study how heavy metals are retained in the different components and hence their solubility, mobility, and bioavailability in contaminated soil (Tessier et al., 1979; Wasay et al., 2001). Such assessments assume that metal bioavailability decreases with each successive extraction step in the procedure. However, apart from conceptual problems associated with the use of sequential extraction (e.g., non-selectivity of the extractants, redistribution of trace element among phases during extraction), proper sample han- 
dling and preparation (e.g., freeze drying, oven drying) remains a major practical problem, because it critically influences the results of a sequential extraction (Rapin et al., 1986). The success of sequential extraction is also affected by such factors as the sequence of the individual steps and specific matrix effects such as cross contamination, $\mathrm{pH}$ buffering and readsorption. Application of single extractions to different sub-sample aliquots (batch system) instead of sequential extractions (continuous flow technique) to the same sub-sample can result in simplified methods involving fewer consecutive steps and shorter treatment time. In this case, all fractions can be simultaneously extracted at the expense of using larger sample amounts. The content of each individual fraction with the exception of the first one is evaluated by subtracting the results obtained in two consecutive stages. So far, this approach proposed originally by Tack et al., (1996) for metal fractionation in sediments provides similar partitioning patterns to sequential extraction except for the organic fraction of the Tessier method. Benefits of a continuous-flow extraction technique as compared with the batch system include the removal of errors associated with repeated centrifugation, filtration and washing. Single extraction is faster than sequential extractions and is likely to minimize re -adsorption problems too.

Heavy metals present in different fractions of soil have different remobilization behaviours under changing environmental conditions. Geochemical forms of heavy metals in soil affect their solubilities, which directly influence their bioavailability (Xian, 1987). Determining total content of heavy metals is insufficient to assess the environmental impact of contaminated soils (Salomons and Forstner, 1980), because it is the chemical form that determines metal behaviour in the environment and its remobilization ability. Total metal concentrations thus provide limited information on the mobility and availability of heavy metals (Karmer and Allen, 1988). Few studies have been carried out on heavy metal contamination of soils in develop- ing countries (Jaradat and Moman, 1999). Therefore, the primary objective of this study was to investigate the chemical partitioning of $\mathrm{Pb}, \mathrm{Cu}, \mathrm{Zn}$ and $\mathrm{Cd}$ in roadside soils along a highway in Ghana in four fractions namely acid soluble, reducible, organic and residual fractions using single extractions.

\section{MATERIALS AND METHODS}

Soil samples were taken between 0 to $15 \mathrm{~cm}$ in depth and from $5 \mathrm{~m}$ to $50 \mathrm{~m}$ from the edge of the road from Tafo to Aboaso in the Ashanti region of Ghana. A total of fifty-four samples were collected from various locations along the road using a plastic shovel. The samples were air dried and ground to pass through a $2 \mathrm{~mm}$ nylon mesh sieve. The extraction scheme, originally proposed by the Community Bureau of Reference (BCR) allows the separation of extractable metals into three fractions: acid soluble, reducible and organic. In this study, the BCR scheme was modified by the inclusion of a residual fraction and the use of single extractions instead of sequential extraction. A summary of the procedure is as follows:

Each soil sample was divided into 4 subsamples and one gram was weighed into a 50 ml-graduated test tube and treated accordingly to obtain the following fractions:

\section{Step 1: Acid soluble fraction (F1)}

An amount of $25 \mathrm{ml}$ of $1 \mathrm{M} \mathrm{NaOAc}$ was added and the sample left at room temperature for 5 hrs with occasional agitation. The result obtained in this step was F1.

\section{Step 2: Reducible fraction (F2)}

An amount of $20 \mathrm{ml}$ of $0.04 \mathrm{M} \mathrm{NH} \mathrm{N}_{2} \mathrm{OH} \cdot \mathrm{HCl}$ in $25 \%(\mathrm{v} / \mathrm{v})$ HOAc was added. The sample was then heated at $96^{\circ} \mathrm{C}$ for $6 \mathrm{hrs}$ with occasional agitation and diluted to $50 \mathrm{ml}$ with deionised water. Since F1 and F2 were extracted together in this step, the reducible fraction (F2) was obtained by subtracting the result from step 1 (F1) from the result in this step.

\section{Step 3: Organic fraction (F3)}

An amount of $3 \mathrm{ml}$ of $0.02 \mathrm{M} \mathrm{HNO}_{3}$ followed 


\section{Adengala et al.}

by $5 \mathrm{ml}$ of $30 \% \mathrm{H}_{2} \mathrm{O}_{2}$ were added. It was heated at $85^{\circ} \mathrm{C}$ for $2 \mathrm{hrs}$ with occasional agitation. Then $3 \mathrm{ml}$ of $30 \% \mathrm{H}_{2} \mathrm{O}_{2}$ was added and heated at $85^{\circ} \mathrm{C}$ for $3 \mathrm{hrs}$ with intermittent agitation followed by $5 \mathrm{ml}$ of $3.2 \mathrm{M} \mathrm{NH}_{4} \mathrm{OAc}$ and heated at $25^{\circ} \mathrm{C}$ for $30 \mathrm{~min}$. The sample was diluted to $20 \mathrm{ml}$ with deionised water and agitated continuously for $30 \mathrm{~min}$. F1, F2 and F3 were extracted together in this step. The organic fraction (F3) was therefore obtained by subtracting the result obtained in step 2 (F1 and F2) from the result in this step.

\section{Total metal content $\left(\mathbf{F}_{\mathrm{T}}\right)$}

An amount of $15 \mathrm{ml}$ aqua regia was added. After leaving it overnight, it was heated at $150^{\circ}$ $\mathrm{C}$ for $1 \mathrm{hr}$ and diluted to $50 \mathrm{ml}$ with deionised water. After each extraction, the sample was filtered using Whatman No. 1 filter paper and the filtrate stored for analysis.

\section{Estimation of the residual fraction (F4)}

The residual fraction (F4) was obtained by estimation. F4 was obtained from the difference between $\mathrm{F}_{\mathrm{T}}$ and the non-residual fraction $(\mathrm{F} 1+$ $\mathrm{F} 2+\mathrm{F} 3$ ).

\section{Analytical Methods}

All extractions were carried out in triplicates in acid-washed labware. All chemicals used in study were of analytical grade. Double deionised water was used. Total metal concentrations were determined by flame atomic absorption spectrophotometry, (AAS) (Spectra AA 220 Varian Spectrophotometer). Standards for all metals were prepared for each extraction procedure in the same matrix as the extracting reagents. The accuracy of the analytical method used was evaluated by performing a recovery analysis. The recovery were found to be within $100 \pm 11.4 \%$

\section{RESULTS AND DISCUSSION \\ Lead}

The amount of $\mathrm{Pb}$ present in the residual fraction ranged from $14.54 \% \quad\left(\mathrm{CP}_{2} \mathrm{~L}_{50} \mathrm{D}_{15}\right)$ to $28.33 \%\left(\mathrm{CP}_{2} \mathrm{~L}_{5} \mathrm{D}_{10}\right)$ with an average of $22.03 \%$ of the total $\mathrm{Pb}$. The non-residual fraction con- tained $77.97 \%$ of the total $\mathrm{Pb}$. Among the nonresidual fraction, lead was mostly concentrated in the reducible fraction. This fraction contained $46.75 \% \quad\left(\mathrm{CP}_{2} \mathrm{~L}_{5} \mathrm{D}_{10}\right)$ to $55.19 \%$ $\left(\mathrm{CP}_{2} \mathrm{~L}_{50} \mathrm{D}_{15}\right)$ with an average of $51.30 \%$ of the total lead. This was in agreement with Chlopecka et al. (1996) and Ramos et al. (1994) who found most of the $\mathrm{Pb}$ to be bound to the reducible and the organic fractions. McKenzie (1980) also reported that Fe and Mn oxides, which make up the reducible fraction, are important scavengers of heavy metals in soils. The acid soluble fraction accounted for $12.78 \% \quad\left(\mathrm{BP}_{1} \mathrm{~L}_{20} \mathrm{D}_{5}\right)$ to $14.95 \% \quad\left(\mathrm{AP}_{2} \mathrm{~L}_{50} \mathrm{D}_{15}\right)$ with an average of $13.90 \%$ and the organic fraction accounted for $11.04 \%\left(\mathrm{BP}_{2} \mathrm{~L}_{20} \mathrm{D}_{5}\right)$ to $15.76 \%\left(\mathrm{CP}_{2} \mathrm{~L}_{50} \mathrm{D}_{15}\right)$ averaging $12.77 \%$ of the total $\mathrm{Pb}$. In general, lead association was in the decreasing order of reducible fraction $>$ residual fraction $>$ acid soluble fraction $>$ organic fraction (Fig. 1).

\section{Zinc}

Zinc was mostly concentrated in the residual fraction, although it was also present in other fractions. As much as $48.45 \%$ of the total $\mathrm{Zn}$ was associated with the residual fraction. The high percentage of $\mathrm{Zn}$ in the residual fraction probably reflects the greater tendency for $\mathrm{Zn}$ to become unavailable once it was in soils. Similar $\mathrm{Zn}$ results were reported for soils from tailing dumps (Jordao and Nickless, 1989) and in near-shore sediments (Gupta and Chen, 1975). About $51.55 \%$ of the total $\mathrm{Zn}$ was associated with the non-residual fractions. Among the non -residual fractions, the reducible fraction contained the highest amount of $\mathrm{Zn}$ in all soils with an average of $39.02 \%$. Levels of $\mathrm{Zn}$ in this fraction ranged from $38.52 \%\left(\mathrm{CP}_{2} \mathrm{~L}_{50} \mathrm{D}_{10}\right)$ to $39.62 \%\left(\mathrm{CP}_{1} \mathrm{~L}_{50} \mathrm{D}_{15}\right)$. Several other workers have also found $\mathrm{Zn}$ to be associated with the reducible fraction (Kuo et al., 1983; Ramos et al., 1994). As little as $6.05 \%$ of total $\mathrm{Zn}$ was associated with the organic fraction. The percentage of $\mathrm{Zn}$ in the acid soluble fraction was $6.49 \%$. Although a large percentage of the total $\mathrm{Zn}$ was in the residual fraction in these soils, the amount of $\mathrm{Zn}$ present in the non-residual 
fractions was also appreciable from the standpoint of potential $\mathrm{Zn}$ mobility and bioavailability.
In general, the association of $\mathrm{Zn}$ in these soils was in the decreasing order of residual fraction $>$ reducible fraction > acid soluble fraction > organic fraction (Fig. 2).

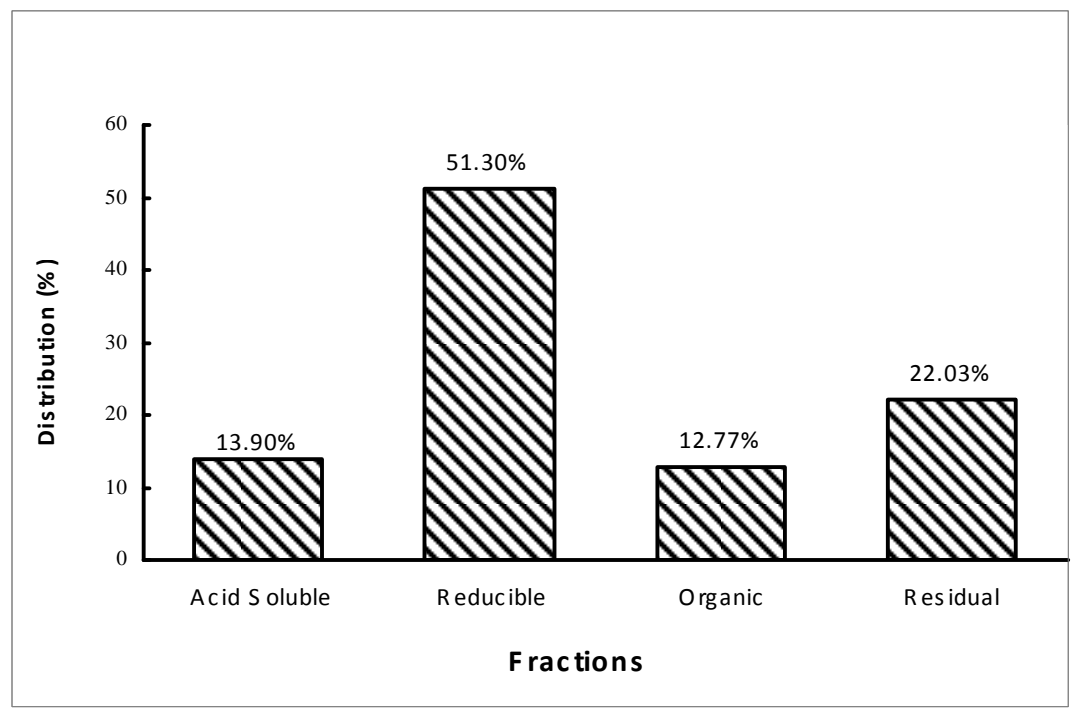

Fig. 1: Distribution of $\mathrm{Pb}$ in various chemical fractions.

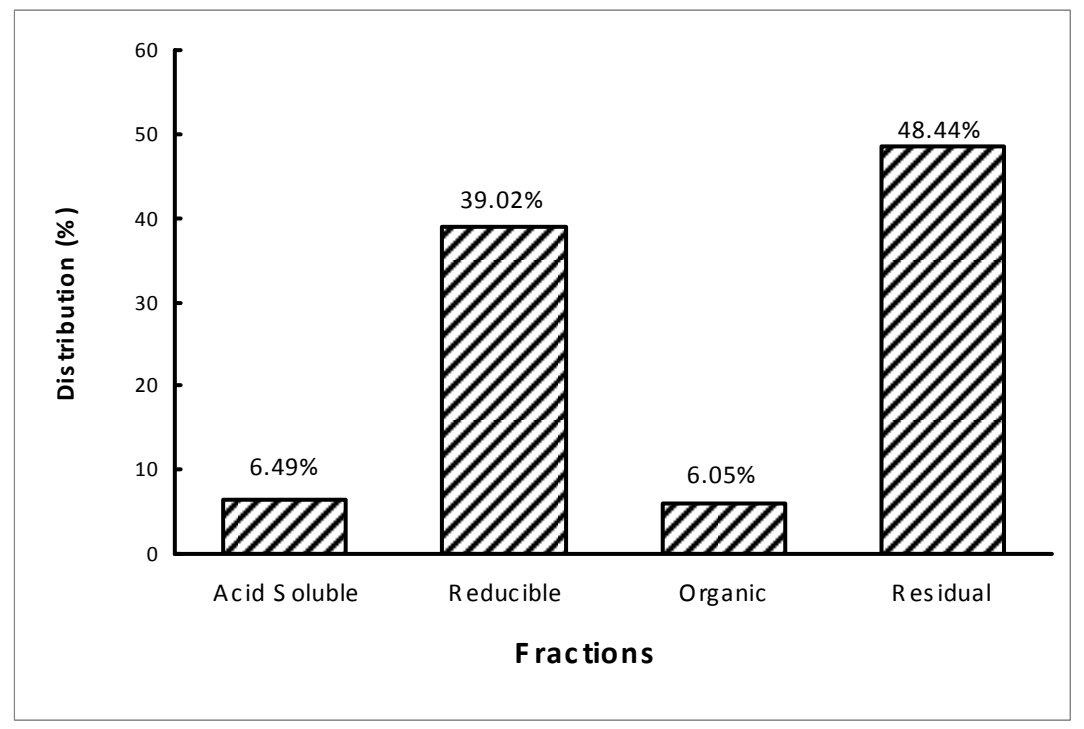

Fig. 2: Distribution of $\mathrm{Zn}$ in various chemical fractions. 


\section{Adengala et al.}

\section{Copper}

The percentage of $\mathrm{Cu}$ associated with the residual fraction was $21.09 \%$. The range was $11.65 \%\left(\mathrm{AP}_{2} \mathrm{~L}_{50} \mathrm{D}_{15}\right)$ to $28.74 \%\left(\mathrm{BP}_{2} \mathrm{~L}_{20} \mathrm{D}_{15}\right)$ The non-residual fraction contained $78.91 \%$ of the total $\mathrm{Cu}$. Among the non-residual fraction, the organic fraction was the most abundant pool for $\mathrm{Cu}$ accounting for $48.44 \%$ of total $\mathrm{Cu}$. This is consistent with the work of Harrison (1981) who found significant amount of $\mathrm{Cu}$ in roadside soils associated with the organic fraction. The major association of $\mathrm{Cu}$ with the organic fraction in soils may be due to high formation constants of organic- $\mathrm{Cu}$ complexes (Stumm and Morgan, 1981). The next important fraction was the reducible fraction, which accounted for $25.54 \%$ of the total $\mathrm{Cu}$. A small percentage of $\mathrm{Cu}$ averaging $4.92 \%$ was associated with the acid soluble fraction. Values ranged from $4.37 \%\left(\mathrm{CP}_{1} \mathrm{~L}_{50} \mathrm{D}_{5}\right)$ to $5.70 \%$ $\left(\mathrm{AP}_{2} \mathrm{~L}_{50} \mathrm{D}_{5}\right)$.

On the average, $\mathrm{Cu}$ association with the various fractions was in the decreasing order: organic fraction $>$ reducible fraction $>$ residual fraction $>$ acid soluble fraction (Fig. 3).

\section{Cadmium}

The percentage of $\mathrm{Cd}$ in the non-residual fractions was much greater than that of the residual fraction. An average of $79.22 \%$ of the total $\mathrm{Cd}$ in the soils was associated with the nonresidual fraction and $20.78 \%$ with the residual fraction. Among the non-residual fractions, the reducible fraction had the highest amount of $\mathrm{Cd}$ ranging from $41.25 \%\left(\mathrm{CP}_{2} \mathrm{~L}_{50} \mathrm{D}_{15}\right)$ to $48.95 \%$ $\left(\mathrm{CP}_{1} \mathrm{~L}_{5} \mathrm{D}_{5}\right)$ with an average of $45.15 \%$ of the total $\mathrm{Cd}$. The percentage of total $\mathrm{Cd}$ associated with the acid soluble fraction was $34.07 \%$ with a range of $28.29 \%\left(\mathrm{AP}_{1} \mathrm{~L}_{20} \mathrm{D}_{10}\right)$ to $40.00 \%$ $\left(\mathrm{AP}_{1} \mathrm{~L}_{20} \mathrm{D}_{15}\right)$. No $\mathrm{Cd}$ was detected in the organic fraction for all samples. This was in agreement with Ma and Rao (1997) who observed that cadmium was present in all fractions when the total $\mathrm{Cd}$ concentration was more than $50 \mathrm{mg} /$ $\mathrm{kg}$. It was not present in the organic fraction when the total concentration was less than 50 $\mathrm{mg} / \mathrm{kg}$.

Generally, Cd association with the various fractions followed the decreasing order: reducible fraction $>$ acid soluble fraction $>$ residual fraction $>$ organic fraction (Fig. 4).

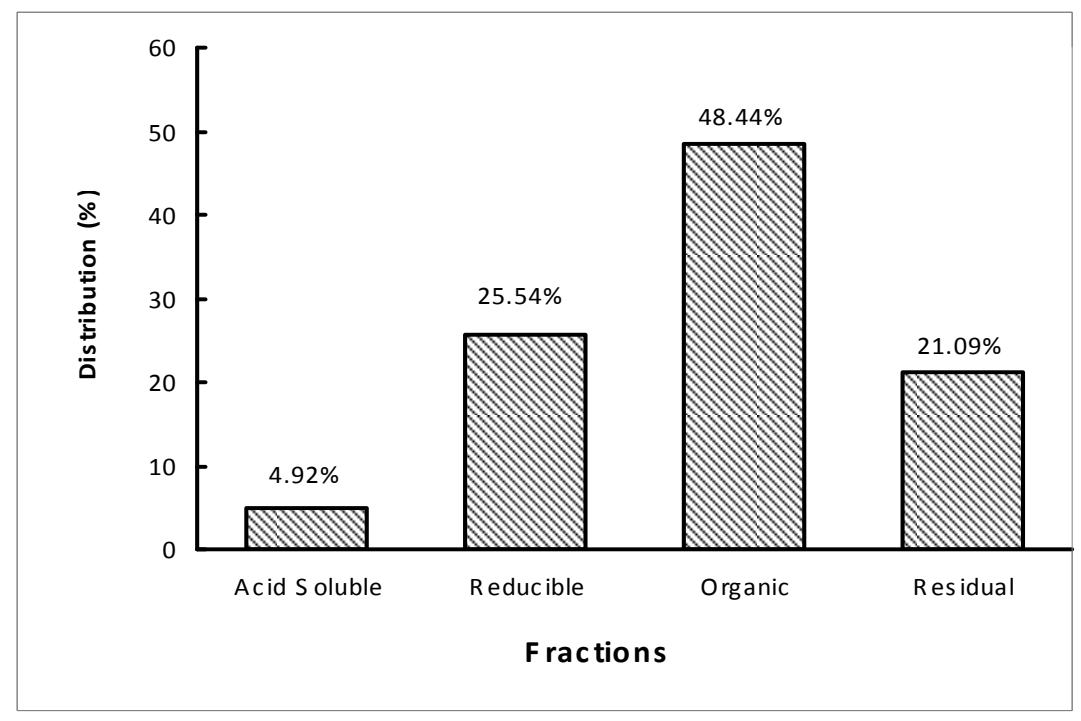

Fig. 3: Distribution of $\mathrm{Cu}$ in various chemical fractions. 


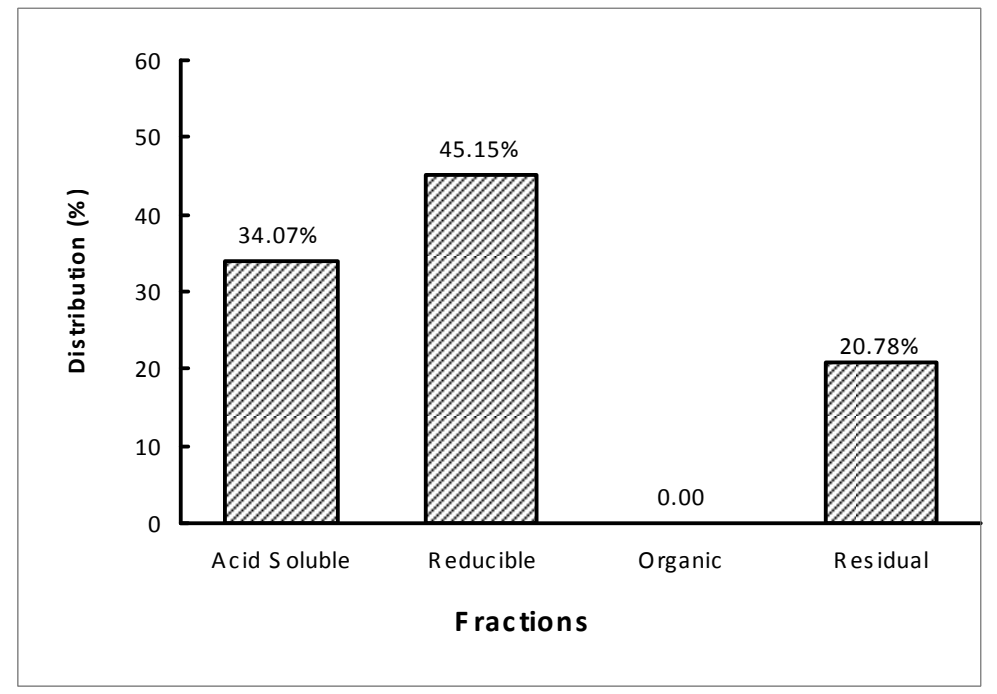

Fig. 4: Distribution of $\mathrm{Cd}$ in various chemical fractions.

The reducible fraction was the most abundant pool for $\mathrm{Pb}$ and $\mathrm{Cd}$. $\mathrm{Cu}$ was mostly associated with the organic fraction and $\mathrm{Zn}$ with the residual fraction. A significant percentage of all the metals occurred in the mobile fraction or nonresidual fraction. The contribution of $\mathrm{Cu}, \mathrm{Cd}$ and $\mathrm{Pb}$ in the potentially bioavailable fractions reached $79.21 \%, 79.16 \%$ and $77.97 \%$ respectively. $\mathrm{Zn}$ occurred mostly in the residual fraction. Its contribution in the potentially bioavailable fraction was $51.55 \%$. Thus the percentages of total $\mathrm{Cu}, \mathrm{Cd}, \mathrm{Pb}$ and $\mathrm{Zn}$ likely to be available to plants are approximately $79.21 \%, 79.16 \%$, $77.97 \%$ and $51.55 \%$ respectively. The order of potential bioavailability of the metals was $\mathrm{Cu}>$ $\mathrm{Cd}>\mathrm{Pb}>\mathrm{Zn}$.

Overall, the order of distribution of the different metals in the different fractions followed the pattern indicated in Fig. 5 below which was

Pb: Reducible fraction > Residual fraction >

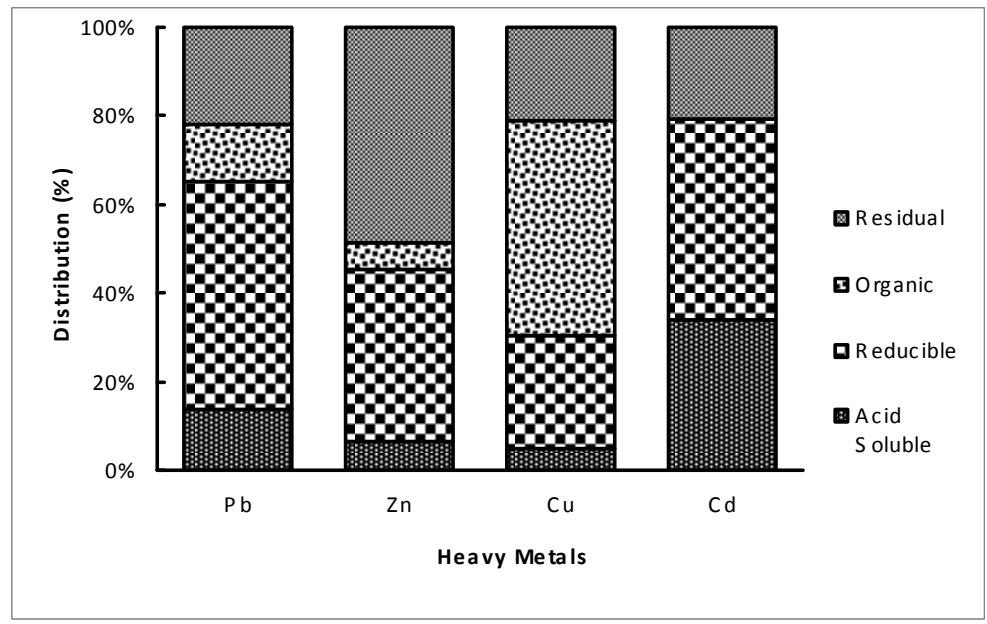

Fig. 5: Comparison of the distribution of lead, zinc, copper and cadmium in various chemical fractions. 


\section{Adengala et al.}

Acid soluble fraction $>$ Organic fraction. Zn: Residual fraction $>$ Reducible fraction $>$ Acid soluble fraction $>$ Organic fraction.

Cu: Organic fraction > Reducible fraction > Residual fraction $>$ Acid soluble fraction.

Cd: Reducible fraction > Acid soluble fraction $>$ Residual fraction > Organic fraction.

\section{CONCLUSION}

Among all the fractions, the reducible fraction was the most abundant pool for $\mathrm{Pb}$ and $\mathrm{Cd}$. $\mathrm{Cu}$ was mostly associated with the organic fraction and $\mathrm{Zn}$ with the residual fraction. This indicates that a significant percentage of the metals tested occurred in the non-residual or mobile fraction. Thus the order of potential bioavailability of the metals to plants is $\mathrm{Cu}>\mathrm{Cd}>\mathrm{Pb}>$ $\mathrm{Zn}$ with percentages of $79.21,79.16,77.97$ and 51.55 respectively.

\section{REFERENCES}

Chlopecka, A., Bacon, J. R., Wilson, M. J. and Kay, J. (1996). Heavy metals in the environment. J. Environ. Qual. 25: 69-79.

Elliot, H. A., Dempsey, B. A. and Maille, M. J. (1990). Content and Fractionation of Heavy Metals in Water Treatment Sludges. J. Environ. Qual. 19: 330-334

Garcia, R. and Millan, E. (1998). Assessment of $\mathrm{Cd}, \mathrm{Pb}$ and $\mathrm{Zn}$ contamination in roadside soils and grasses from Gipuzkoa (Spain). Chemosphere, 37: 1615-1625.

Goldsmith, C. D., Scanlon, P. F. and Pirie, W. R. (1976). Lead concentrations in soil and vegetation associated with highways of different traffic densities. Bull. Environ. Contam. Toxicol. 16: 66-70.

Gupta, S. K. and Chen. K. Y. (1975). Partitioning of trace metals in selective chemical fractions of nearshore sediments. Environ. Lett. 10: 129-158.

Harrison, R. M., Laxen, D. P and Wilson, S. J. (1981). Chemical association of lead, cad- mium, copper and zinc in street dusts and roadside soils. Environ. Sci. Technol. 15: 1378-1389.

Hickey, M. G. and Kittrick, M. G. (1984). Chemical partitioning of cadmium, copper, nickel, and zinc in soils and sediments containing high levels of heavy metals. J. Environ. Qual. 13: 372-376.

Ho, Y. B. and Tai, K. M. (1988). Elevated levels of lead and other metals in roadside soil and grass and their use to monitor aerial metal depositions in Hong Kong. Environ Pollut. 49: 37-51

Jaradat, Q. M. and Moman, K. A. (1999). Contamination of roadside soil, plants and air with heavy metals in Jordan, A Comparative Study. Turk J. Chem. 23: 209-220

Jaradat, Q. M. (2002a). Fractionation and distribution of heavy metals in street dust in Amman, Jordan. Mu'tah Lil-Buhuth wadDirasat. 17(3): 105-118.

Jordao, C. P. and Nickless, G. (1989). Chemical association of $\mathrm{Zn}, \mathrm{Cd}, \mathrm{Pb}$ and $\mathrm{Cu}$ in soils and sediments determined by the sequential extraction technique. Environ. Technol. Lett. 10: 743-752.

Karmer, J. R. and Allen, H. E. (1988). Metal Speciation. Lewis Publishers, MI, USA.

Krishnamurti, G. S. R., Cieslinski, G., Huang, P. M. and Van Rees, K. C. J. (1997). Kinetics of cadmium release from soils as influenced by organic acids: Implication in cadmium availability. J. Environ. Qual. 26: $271-277$.

Kuo, S., Heilman, P. E. and Baker, A. S. (1983). Distribution and forms of copper, zinc, cadmium, iron and manganese in soils near a copper smelter. Soil Sci. 135: 101-109. 
Lund, W. (1990). Speciation analysis - why and how? Fresenius J. Anal. Chem. 337: 557564.

Ma Lena Q. and Rao Gade N. (1997). Chemical Fractionation of Cadmium, Copper, Nickel and Zinc in Contaminated Soils. J. Environ. Qual. 26: 259-264

McKenzie, R. M. (1980). The adsorption of lead and other heavy metals on oxides of manganese and iron. Aust. J. Soil Res. 18: 61-73.

Meguellati, N., Robbe, D., Marchandise, P. and Astruc, M. (1983). Proc. Int. Conf. Heavy Metals in the Environment, ed. G. Müller, CEP Consultants, Edinburgh, vol. 2.

Motto, H. L., Daines, H. R.., Chilko, D. M. and Motto, K. C. (1970). Lead in soils and plants: its relation to traffic volume and proximity to highways. Environ. Sci. Technol. 4: 231-237.

Page, A. L., Miller, R. H. and Keeney, D. R. (1971). Methods of soil analysis. Part 2. Chemical and Microbiological Properties, pp. 539-579.

Pickering, W. F. (1981). Selective chemical extraction of soil components and bound metal species. Critical review. Anal. Chem. 12: 233-266.

Ramos, L., Hernandez, L. M. and Gonzalez, M. J. (1994). Sequential extraction of copper, lead, cadmium and zinc in soils from the near Donana national park. J. Environ. Qual. 23: 50-57.

Rapin, F., Tessier, A., Campbell, P. G. C. and Carignan, R. (1986). Potential artifacts in the determination of metal partitioning in sediments by a sequential extraction procedure. Environ. Sci. Technol. 20: 836-840.

Salomons, W. and Förtsner, U. (1980). Trace metal analysis on polluted sediments. Environ. Technol. Lett. 1: 506-517

Shuman, L. M. 1985. Fractionation method for soil microelements. Soil Sci. 140: 11-22.

Stumm, W. and Morgan, J. J. (1981). Aquatic chemistry: An introduction emphasizing chemical equilibria in natural waters. 2nd ed. John Wiley \& Sons, New York.

Tack, F. M. G and Verloo, M. G. (1995). Chemical speciation and fractionation in soil and sediment heavy metal analysis: A Review. Intern. J. Environ. Anal. Chem. 59: 225-238.

Tack, F. M. G., Vossius, H. A. H. and Verloo, M. G. (1996). A comparison between sediment metal fractions obtained from sequential extraction and estimated from single extractions. Intern. J. Environ. Anal. Chem. 63: 61-66.

Tam, N. F. Y., Liu, W. K., Wang, M. H. and Wong, Y. S. (1987). Heavy metal pollution in roadside, urban parks and gardens in Hongkong. Sci. Total. Environ. 59: 325328.

Tessier, A., Campbell, C. and Bisson, M. (1979). Sequential extraction procedure for the speciation of particulate trace metals. Anal. Chem. 51: 844-885.

Ure, A. M. (1990). Trace elements in soil: their determination and speciation. Fresenius $J$. Anal. Chem. 337: 577-581.

Ure, A. M., Davidson, C. M and Thomas, R. P. (1995). Quality Assurance for environmental analysis, ed. Ph. Quevauviller, E. A. Maier and Griepink, B., Elsevier, Amsterdam, pp. 505-523

Ure, A. M. and Davidson, C. M. (2001). Chemical Speciation in the Environment, Blackie, Glosgow, pp. 265-321. 
57 Adengala et al.

Ward, N. I., Reeves, R. D, and Brooks, R. R. (1977). Lead in soil and vegetation along a New Zealand state highway with low traffic volume. Environ. Sci. Tchnol. 11: 91720.

Wassay, S. A., Parker, W. J. and Van Geel, P. J. (2001). Characterization of soil contami- nated by disposal of battery Industry waste. Can. J. Civil Eng. 28: 341-348.

Xian, X. (1987). Chemical partitioning of cadmium, zinc, lead and copper in soils near smelters. J. Environ. Sci. Health. 6:527541 . 